\title{
Analytical Needs in Agribusiness
}

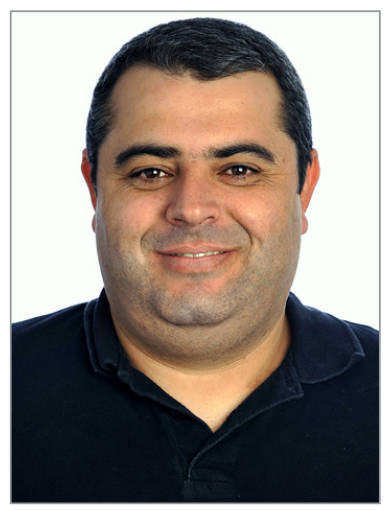

\author{
Fernando Vitorino da Silva \\ Chemistry Laboratory Manager \\ Nestle Quality Assurance Center - Brazil \\ fernando.silva2@br.nestle.com
}

Sustainable agriculture is the efficient production of safe, high quality agricultural products in a way that protects and improves the natural environment, the social and economic conditions of farmers, and their employees and local communities, as well as safeguards the health and welfare of all farmed species. By supporting sustainable development in agriculture, it is possible to contribute to the processes that increase the world's access to higher food quality and, therefore, contribute to longterm social and economic development, preserving the environment for future generations. This set of practice, at its highest level, is oriented along four natural capital themes: soil, biodiversity, greenhouse gases emissions, and water. Sustainable initiatives build a continuous improvement approach to reach sustainable intensification of agriculture production systems. Managing food safety and quality in agricultural production implies that we inform and train farmers and suppliers on pre- and postharvest practices, including storage and transportation of raw materials, ensuring the application of best practices to maintain high quality of raw materials. To control the efficiency of these preventative actions on the food chain, quality management should apply controls fitted for this purpose. Considering controls implemented on whole food chain production, analytical science has an important role in assessing compliance status with strict quality standards and controls of residue levels or contamination by microbiological pathogens, mycotoxins, heavy metals, and pesticides. Food safety science has experienced intense development over the last 20 years and most of this improvement is associated with advance of analytical science and laboratory instrumentation. Several controls and inspection not feasible at past, nowadays became reality on supply chain of food industry, where agribusiness acts as big player of raw material sourcing. Today, by using rapid methods for multi-screening procedures, veterinary drugs or mycotoxins can be quickly controlled at affordable cost on commodities like milk and cereals. The advance of instrumentation also allows remote monitoring of nutrient soil condition, on frame of precision agriculture, avoiding use of classic and time-consuming methods for test control. The availability of portable devices and rapid methods empowers the farmer to take quick action in quality control, bringing complex tests usually only performed in laboratories to the field. This will be become a trend for the next generations. 